\title{
A balanced approach to interpreting the WHIRCDMT
}

To the Editor: I read with interest the critique of the Women's Health Initiative Randomized Controlled Dietary Modification Trial (WHIRCDMT) ${ }^{[1]}$ by Prof. Tim Noakes. ${ }^{[2]}$ His critique focused on the varying incidence of cardiovascular outcomes between women with and without a history of cardiovascular disease (CVD), and justly called for more discussion and transparency with respect to these findings. The latter half of the critique, however, unfairly portrays the low-fat dietary intervention as deleterious for weight gain and the development of diabetes mellitus (DM).

First, Prof. Noakes should be applauded for raising awareness around what many researchers and clinicians would characterise as the disappointing findings of the WHIRCDMT. Additionally, his discussion on the potentially negative effects of a low-fat diet in women with prior history CVD or DM is illuminating. Evidence from other studies supports the idea that reducing dietary fat without paying attention to the composition of foods substituting it can have deleterious effects. ${ }^{[3]}$

Several of the criticisms of the WHIRCDMT, however, were exaggerated or misleading. Specifically, Prof. Noakes states that for women randomised to the intervention group, 'the leanest women 
at the start of the trial gained weight on the low-fat $\operatorname{diet}^{\left[{ }^{[2]}\right.}$ While the leanest women in the intervention group did indeed gain weight, this was also true for the leanest women in the control group. ${ }^{[4]}$ In fact, women in the intervention group had significantly lower weight than those in the control group among women with a body mass index $<25 \mathrm{~kg} / \mathrm{m}^{2}$ at baseline ${ }^{[4]}$ May this result simply reflect that the leanest women were more susceptible to weight gain, regardless of assigned diet? It is important to remember that this trial was conducted at the same time that prevalence of obesity in the US increased, ${ }^{[5]}$ and increases in weight for a proportion of participants would be expected due to myriad changes in the environment.

A second issue with Prof. Noakes' critique is the statement that, 'those with the least insulin resistance at the start of the trial were at greater risk of developing type $2 \mathrm{DM}$ if assigned to the low-fat diet. ${ }^{\left[{ }^{[2]}\right.} \mathrm{He}$ is correct that there was a significant interaction between intervention assignment and glycaemic control markers (insulin and homeostasis model assessment, insulin resistance). ${ }^{[6]}$ In truth, however, there were no detectable differences between individual tertiles, ${ }^{[6]}$ which limits the ability to make causative statements regarding subgroups. What is more, the absolute counts in the lowest tertiles were extremely small, mostly because data on glycaemic measures were available for only 2 816/45 887 participants. ${ }^{[6]}$ Moreover, the true significance of any subgroup analysis should be viewed with scepticism. In effect, these analyses remove the protection from confounding that randomisation provides, and unless subgroup analyses are done only on a few, pre-specified endpoints, they can lead to erroneous conclusions. ${ }^{[7]}$ Thus, Prof. Noakes' statement seems, at a minimum, overly confident regarding the effects of a low-fat dietary intervention for the primary prevention of DM.

Prof. Noakes' critique of the WHIRCDMT highlights several issues with the prescription of a low-fat diet, including the variability of effectiveness for different groups in the population. In particular individuals with pre-existing CVD and DM may experience harmful effects when attempting to follow a low-fat diet. Nevertheless, the WHIRCDMT does not provide high-quality evidence that a lowfat diet emphasising fruits, vegetables and whole grains contributes disproportionately to the development of DM and weight gain.

While it can be agreed the WHIRCDMT was disappointing in many ways for researchers and clinicians alike, a more balanced approach to the interpretation of the results is warranted.

\section{Patrick B Wilson}

School of Kinesiology, University of Minnesota, Minneapolis, USA wilso733@umn.edu

1. Howard BV, Van HL, Hsia J, et al. Low-fat dietary pattern and risk of cardiovascular disease: The Women's Health Initiative Randomized Controlled Dietary Modification Trial. JAMA 2006;295(6):655666. [http://dx.doi.org/10.1001/jama.295.6.655]

2. Noakes TD. The Women's Health Initiative Randomized Controlled Dietary Modification Trial: An inconvenient finding and the diet-heart hypothesis. S Afr Med J 2013;103(11):824-825. [http://dx.doi. org/10.7196/SAMI.7343]

3. Jakobsen MU, O'Reilly EJ, Heitmann BL, et al. Major types of dietary fat and risk of coronary heart disease: A pooled analysis of 11 cohort studies. Am J Clin Nutr 2009;89(5):1425-1432. [http://dx.doi. disease. A pold analysis of 11

4. Howard BV, Manson JE, Stefanick ML, et al. Low-fat dietary pattern and weight change over 7 years: The Women's Health Initiative Dietary Modification Trial. JAMA 2006;295(1):39-49. [http://dx.do org/10.1001/jama.295.1.39]

5. Mokdad AH, Serdula MK, Dietz WH, et al. The spread of the obesity epidemic in the United States 1991-1998. JAMA 1999;282(16):1519-1522. [http://dx.doi.org/10.1001/jama.282.16.1519]

6. Tinker LF, Bonds DE, Margolis KL, et al. Low-fat dietary pattern and risk of treated diabetes mellitus in postmenopausal women: The Women's Health Initiative Randomized Controlled Dietary Modificatio Trial. Arch Intern Med 2008;168(14):1500-1511. [http://dx.doi.org/10.1001/archinte.168.14.1500] 7. Rothwell PM. Subgroup analysis in randomised controlled trials: Importance, indications, and
interpretation. Lancet 2005;365(9454):176-186. [http://dx.doi.org/10.1016/S0140-6736(05)17709-5]

S Afr Med J 2014;104(3):157-158. DOI:10.7196/SAMJ.7839 